\title{
Nanoparticles Constructed from Neosartorya hiratsukae to Control Drechslera oryzae Causing Brown Spot of Rice
}

\author{
Kessara Unthuraloet, and Kasem Soytong* \\ Department of Plant Production Technology, Faculty of Agricultural Technology, King Mongkut's Institute of \\ Technology Ladkrabang (KMITL), Bangkok, Thailand. \\ *Corresponding author. Email: ajkasem@gmail.com
}

\begin{abstract}
The toxic chemical fungicides for plant disease control has been used by farmers for years. Those are faced hazardous effect to the surrounding environment, and the chemicals were toxic chemical residue remained in rice products which harmful to the consumers. It is increasing interested to search the new biological control agent to control the pathogen and to be promising as a biocontrol agent against the rice bast incidence in seriously infested rice fields. The aims of project was proved the fungus Neosartorya hiratsukae as a biological control agent to brown spot of rice (Oryza sativa) caused by Drechslera oryzae and developed a novel nanoparticles constructed from $N$. hiratsukae to control the rice brown spot. Result revealed that the aggressive isolate of $D$. oryzae was significantly inhibited by $N$. hiratsukae antagonistic fungus in bi-culture antagonistic evaluation. The growth of $D$. oryzae in bi-culture test was inhibited fungal colony and sporulation by 51 and 55 $\%$, respectively. Bioassay of crude metabolite extract by methanol from $N$. hiratsukae gave the good inhibition of the colony growth and sporulation of $D$. oryzae which the $\mathrm{ED}_{50}$ of 1.7 and 92 ppm., respectively. The nanoparticles constructed from $N$. hiratsukae using electron spinning method found that nanoparticles SH-M expressed the best inhibition of the pathogen growth both colony and sporulation of the tested rice pathogen with the $\mathrm{ED}_{50}$ of $4 \mathrm{ppm}$. It is observed that nanoparticles SH-M had more effective control the pathogen than crude metabolite extract from $N$. hiratsukae. Pot experiment showed that nanoparticles SH-M actively expressed antifungal activity against brown spot of rice more than the inoculated control. It is interested that the rice plants treated with nanoparticles SH-M resulted to be better plant stands than the inoculated control. This is recorded for the first time using new antagonist, $N$. hiratsukae and its active compounds both in crude extracts and nanoparticles to control brown spot of rice.
\end{abstract}

\section{Keywords: Neosartorya hiratsukae, rice, brown spot, rice, nanotechnology}

\section{INTRODUCTION}

The major food crops in Asia is rice (Oryza sativa L.) It is the most widely consumed staple food of the world population in Asia and the West Indies. It is the thirdhighest production in the world FAO. [1] Drechslera oryzae (Breda de Haan) Subram. \& Jain causing rice brown leaf spot become epidemic disease in Thailand and Cambodia. Brown leaf spot of rice can infect the stems in seedlings and mature plants. The symptom showed blight in brown colour on leaves, and seedlings where grown from infected seeds [2]. It causes brown spot of rice leaves especially in seedling stage. It spreads to the rice fields which causing seedlings death until 58\% [3, 4] Chemical fungicides are applied to control the disease by the rice growers and the repeatedly application of chemical fungicides leading development of pathogen resistant to those chemicals. The antagonistic fungi against plant pathogens has been widely searched to control the diseases. Tathan et al. [5] stated that antagonistic fungi Chaetomium spp., Chaetomium cochliodes, Chaetomium cupreum, Chaetomium brasilense, Chaetomium elatum and Chaetomium globosum effectively supressed leaf spot pathogen of rice caused by $D$. oryzae. These Chaetomium spp. are reported to produce bioactive metabolites to inhibit the sporulation of D. oryzae. Recently, Neosartorya hiratsukae used in this experiment is reported to produce chevalone $\mathrm{G}$ and aszonapyrone $\mathrm{C}$, 7-chlorofischerindoline and brasiliamide $\mathrm{H}$ that inhibited Escherichia coli, Bacillus cereus, Pseudomonas aeruginosa and Salmonella enterica serovar typhimurium. Moreover, N. hiratsukae also reported tom produce 7-chlorofischerindoline that 
expressed cytotoxicity to HeLa, HepG2, HT-29, KB, MCF7 , and Vero cell lines with the IC50 ranged from 45 to ppm 63. [6]. Many researchers found this antagonistic fungi, Neosartorya fischeri, Neosartorya glabra, Neosartorya hiratsukae, Neosartorya takakii, and Neosartorya tatenoi against chilli anthracnose caused by Colletotrichum capsici [7, 8] N. hiratsukae, Neosartorya pseudofischeri, Neosartorya aureola, Neosartorya spinosa, and Neosartorya fennelliae also proved to control leaf spot of kale caused by Alternaria brassicicola [9]. Moreover, $N$. hiratsuka EU06 actively inhibited Phomosis asparagi causing asparagus anthracnose over $59 \%$. The objective of reserch project was evaluated the nanoparticles constructed from $N$. hiratsukae strain MST to control D. oryzae causing brown leaf spot of rice.

\section{MATERIALS AND METHODS}

\subsection{Isolation of Drechslera oryzae causing brown leaf spot of rice (Oryza sativa)}

The sample of brown leaf spot symptom was isolated by tissue transplanting method. The advanced margin from disease lesion was placed on water agar medium and maintained at room temperature (28-30 C). The hyphal tips were moved to potato dextrose agar (PDA) to receive pure culture.

\subsection{Antagonistic fungus, Neosartorya hiratsukae strain MST}

The antagonistic fungus, Neosartorya hiratsukae MST is obtained from Biological control Research Unit, Agricultural Technology Faculty, King Mongkut's Institute of Technology Ladkrabang (KMITL), Bangkok, Thailand.

\subsection{Pathogenicity test}

The isolated pathogen was proved to be pathogenic isolate according to Koch's Postulate.by detached leaf method The agar plugs of fungal pathogen were inoculated onto the wounded leaves of rice var KorKor1. The agar plugs without fungal pathogen were transferred onto wounded leaves served as controls. The experiment was set up as Completely Randomized Design (CRD) with four replications. The inoculated and non-inoculated pathogen on the wounded leaves were incubated in moist chambers at room temperature of 27-30 $\mathrm{C}$ for 7-10 days until the lesions appeared. The infected leaves were re-isolated to get the pure isolate of the same pathogen. Disease index was scored as $0=$ no symptom and $10=76-100 \%$ leaf blight [10].

\subsection{Bi-culture test between Neosartorya hiratsukae MST and Drechslera oryzae}

$N$. hiratsukae was evaluated to inhibit $D$. oryzae causing brown leaf spot of rice var Korkor1. Completely
Randomized Design (CRD) was arranged with 4 repeated experiments. The tested antagonists was separately cultured on potato dextrose agar (PDA) at room temperature $\left(30^{\circ} \mathrm{C}\right)$ for 15 days. The antagonistic agar plugs of $0.5 \mathrm{~cm}$ were cut from actively growing edge of cultures, then transferred to PDA plates at one side and the agar plugs $(0.5 \mathrm{~cm})$ of tested pathogen was transferred at opposite side in bi-culture plates. The agar plugs of $N$. hiratsukae and $D$. oryzae were separately moved to PDA plates which served as the controls. Bi-culture plates were incubated at room temperature $\left(30^{\circ} \mathrm{C}\right)$ for 20 days. Colony diameter $(\mathrm{cm})$ and sporulation in bi-culture plates and control plates were measured using haemacytometer. The inhibition of colony growth and sporulation of $D$. oryzae were calculated by the following formula: $\%$ inhibition $=(A-B) / A \times 100$, where, $\mathrm{A}$ is colony diameter or sporulation in bi-culture and control plates, and B represented the colony diameter or sporulation in the bi-culture plate. Data were calculated analysis of variance (ANOVA) and means were compared using Duncan Multiple's Range Test (DMRT) at $\mathrm{P}=0.05$.

\subsection{Crude extracts of Neosartorya hiratsukae MST testing against Drechslera oryzae}

The crude extracts of $N$. hiratsukae was tested for inhibition of $D$. oryzae. The experiment was designed in $3 \times 6$ factorial in Completely Randomized Design (CRD) with repeated experiments. The crude hexane, ethyl acetate and methanol extracts were in combination with the concentrations of $0,10,50,100,500$ and 1,000 ppm. Each crude extract was dissolved $2 \%$ dimethyl sulfoxide, mixed into PDA, then autoclaved at $121^{\circ} \mathrm{C}, 15 \mathrm{lbs}$ for $30 \mathrm{mins}$. The pathogenic isolate of D. oryzae was transferred its agar plug to the middle of PDA incorporated with the extract. The tested plates were incubated at room temperature and observed until $D$. oryzae in the control plates grew in full plate. Data were gathered spore number and colony diameter $(\mathrm{cm})$, then statistically computed ANOVA and mean comparison was calculated using DMRT) at $\mathrm{P}=0.05$. The probit analysis program was computed the effective dose $\left(\mathrm{ED}_{50}\right)$.

\subsection{Natural products nano-particles from Neosartorya hiratsukae MST testing against Drechslera oryzae}

The nano-particles constructed from Neosartorya hiratsukae (nano $\mathrm{NH}-\mathrm{H}$, nano-NH-E, nano-NH-M) were offered from Biological control Research Unit, Faculty of Agricultural Technology, KMITL, Bangkok, Thailand. Two factors factorial experiment in CRD was performed with four repeated experiments. Nano NH-H, nano-NH-E, nano-NH-M were tested in combination with the concentrations of $0,1,3,5,7$ and $10 \mathrm{ppm}$. The method was followed the above experiment. 
2.7. Pot experiment testing for efficacy of nanoparticles from Neosartorya hiratsukae MST to control brown leaf spot of rice

Randomized completely block design (RCBD) was performed with four repeated experiments. Treatments were set up as follows: $\mathrm{T} 1=$ inoculated control, $\mathrm{T} 2=$ nano-NH-M derived from $N$. hiratsukae MST at the concentration of 10 ppm, and T3= carbendazim fungicide $(1 \mathrm{~g} / 1 \mathrm{~L}) .15$ seedlings of rice var Korkor 1 were plants in pots containing sterilized soil in each experimental unit. The tested pathogen, $D$. oryzae was cultured on PDA for 15 days before collecting the conidia to make inoculate $1 \times 10^{5}$ spores $/ \mathrm{ml}$. All tested plants were inoculated by spraying onto the wounded lesion on leaves. The inoculated plants were sprayed either nanoNH-M or carbendazim fungicide, and maintain in greenhouse for one month. The plant height $(\mathrm{cm})$, fresh and dried weight of plants $(\mathrm{g})$. were recorded Disease index was scored as $1=$ no symptom, $2=1-25 \%, 3=26-50 \%$, 52 $75 \mathrm{v} \%, 76-100 \%$

\section{RESULTS AND DISCUSSION}

\subsection{Isolation of Drechslera oryzae causing brown leaf spot of rice (Oryza sativa)}

Drechslera oryzae was isolated and identified to be causal agent of brown leaf spot. It was proved to be aggressive isolate to cause the disease according to Koch's postulate. D. oryzae belongs to Pleosporaceae, Kingdom Fungi. The fungus grew on PDA for 19 days with brown black in color of colony. It produces conidia on conidiophore either in the top or side of conidiophore, conidia 3-9 septa (Fig. 1). With this, brown leaf spot of rice is reported to infect rice either in seedlings or mature plants [2].

\subsection{Antagonistic fungus, Neosartorya hiratsukae strain MST}

The fungus belongs to Eurotiaceae, Ascomycotina, Kingdom Fungi. Colony is white color in PDA at 30 days. It produces perithecia which contain many asci which rounded shape or ovate, 8 -ascospore/ascus and ascospores have ridges along the ascopores (Fig.2).

\subsection{Pathogenicity test}

The isolated Drechslera oryzae was proved to be pathogenic to rice var Korkor2 causing brown leaf spot. The inoculated pathogen had high disease index of level 5. The non-inoculated control had no infection (Fig. 3). D. oryzae is reported to cause brown leaf spot of rice in seedling stage [4].

\subsection{Bi-culture test between Neosartorya hiratsukae strain MST and Drechslera oryzae}

Bi-culture test showed $N$. hiratsukae strain MST actively inhibited the tested pathogen, D. oryzae at $52 \%$ and inhibited spore production of $56 \%$ in 10 days. It observed that $N$. hiratsukae grown over the colony of $D$. oryzae causing brown spot of rice var Korkor1. Result was similar to report that Neosartorya species could be controlled other phytopathogens which inhibited Colletotrichum coffeanum causing coffee antracnose [11] and Neosartorya aureola, Neosartorya fenneliae, Neosartorya hiratsukae, Neosartorya pseudofischeri, Neosartorya spinosa actively suppressed Colletotrichum musae causing banana anthracnose in dual culture tests [12]. Moreover, Phomopsis asparagi causing asparagus stem blight was reported to Neosatorya spp. [9] and Alternaria brassicicola causing leaf spot of kales was inhibited by $N$. aureola, $N$. fennelliae N. hiratsukae, N. pseudofischeri and N. spinosa, [8].

\subsection{Crude extracts of Neosartorya hiratsukae strain MST testing against Drechslera oryzae}

The biomass of Neosartorya hiratsukae strain MST were extracted to yield crude hexane, crude, crude ethyl acetate and crude methanol (Fig.5). Results showed that crude hexane extracted from $N$. hiratsukae at 10, 50, 100, 500 and $1,000 \mathrm{ppm}$ eliminated the sporulation of $D$. oryzae at $43,38,34,36$ and $48 \%$, respectively. Crude ethyl acetate extract at 10, 50, 100, 500 and 1,000 ppm eliminated sporulation of $14,9,40,50$ and $55 \mathrm{v} \%$, respectively. Crude methanol gave the highest spore inhibition at 10, 50, 100, 500 and 1,000 ppm, 66, 91, 95, 96, $97 \%$, respectively (Table 1 , Fig.6). Similar result stated that nanoparticles derived from Chaetomium brasiliense namely nano-CBM at $10 \mathrm{ppm}$ inhibited D. oryzae causing brown spot of rice [13]. With this, The other antagonistic fungi, Chaetomium brasilense, ,Chaetomium cochliodes, Chaetomium cupreum, Chaetomium elatum and Chaetomium globosum were reported to antagonize $D$. oryzae causing brown leaf spot of rice [5]. The research findings were in related with reports on crude extracts of Neosartorya spp. used to control C. coffeanum (coffee anthracnose) [11]. Fungal metabolites from Neosartorya aureola, Neosartorya fenneliae, Neosartorya hiratsukae, Neosartorya pseudofischeri and Neosartorya spinosa and inhibited C. musae causing wilt of banana [12]. Crude extracts derived from $N$. hiratsukae, N. pseudofischeri, N. aureola, $N$. spinosa, N. fennelliae reported to inhibit A. brassicicola (leaf spot of kales) [8]. Moreover, the active metabolites extracted from Neosartorya spp. were reported to inhibit Phomopsis asparagi (asparagus stem blight) [9]. It concluded that methanol crude extract gave the best result to inhibit $D$. oryzae which the $\mathrm{ED}_{50}$ value of $1.5 \mathrm{ppm}$, and followed by crude ethyl acetate extract which the $\mathrm{ED}_{50}$ value of $544 \mathrm{ppm}$. 


\subsection{Natural products nano-particles from Neosartorya hiratsukae testing against Drechslera oryzae}

Crude hexane, crude ethyl acetate and crude methanol derived from $N$. hiratsukae strain MST were constructed by electron spinning technique to yield nanoparticles, nano-NHH, nano-NHE and nano-NHM, respectively according to the method of Dar et al. [14] The characterics of nanoparticles contrasted from $N$. hiratsukae strain MST can be seen in Fig. 7. The constructed nano particles from crude extracts of $N$. hiratsukae showed that nano-NHH inhibited the colony growth of $D$. oryzae at concentrations of $1,3,5,7$ and $10 \mathrm{ppm}$ which were 28, 31, 40, 49 and $54 \%$, respectively which the $\mathrm{ED}_{50}$ value of $7.7 \mathrm{ppm}$ (Table 2). Nano-NHE inhibited the tested pathogen at 1,3, 5, 7 and $10 \mathrm{ppm}$. Which were 40, 41, 41,55 and $60 \%$, respectively which the $\mathrm{ED}_{50}$ value of 5.28 ppm Nano-NHM inhibited the colony growth at 1, 3, 5, 7 and $10 \mathrm{ppm}$ which were $40,40,44,54$ and $64 \%$, respectively which the $\mathrm{ED}_{50}$ value of $4.73 \mathrm{ppm}$. Spore production of $D$. oryzae causing brown leaf spot of rice var Korkor1 was inhibited by nanoparticles derived from $N$. hiratsukae. $\mathrm{NHH}$ at concentrations of 1, 3 Nano, 5, 7 and $10 \mathrm{ppm}$. inhibited spore production of $D$. oryzae of $15,27,33,68$ and $88 \%$, respectively. Spore inhibition of the tested pathogen was shown in nano-NHE at concentrations of 1, 3, 5, 7 and $10 \mathrm{ppm}$ which were 20, 20, 44, 70 and $93 \%$, respectively. Nano-NHM showed that the production of pathogenic spores was increased from 1 to $10 \mathrm{ppm}$, concentrations at 1, 3, 5, 7 and $10 \mathrm{ppm}$ inhibited spore production of $15,16,39,65$ and $94 \%$, respectively (Table 3 ). The $\mathrm{ED}_{50}$ values of nano-NHH, nanoNHE and nano-NHM to inhibit D. oryzae were 4.6, 4.11 and $4.63 \mathrm{ppm}$, respectively. D. oryzae causing brown leaf spot of rice was inhibited by crude hexane, ethyl acetate and methanol extracted from Chaetomium cochliodes which value of $\mathrm{ED}_{50}$ value was $66.45 \mathrm{ppm}$. [15].

The agricultural nanotechnology is started to be a new tool for plant disease management by restructuring natural active metabolites at the molecular level. The nanomaterials contain bioactive compounds rapidly and effectively penetrated through plant tissues and cells and help to increase the stability of active compounds to control plant disease. It was reported that natural product of nano-particles derived from Ch. cochliodes CTh05 actively inhibited Magnaporthe oryzae causing rice blast for the first time [16]. Moreover, there were reported that nano-CCoM at $7 \mu \mathrm{g} / \mathrm{mL}$, followed by nanoCCoE and nanoCCoH derived from Chaetomium cochliodes isolate CTh05 could be reduced the blast infection in 30 days. Further report on antifungal efficacy of microbial nano-particles constructed from Chaetomium elatum, against rice blast pathogen in rice var. PSL 2 in Thailand was stated that nano-CEE, nano-CEM and nano-CEH inhibited sporulation of M. oryzae which the ED50 values of 7.89, 8.66 and $16.7 \mu \mathrm{g} / \mathrm{mL}$. respectively [17].

\subsection{Pot experiment testing for efficacy of nano- NHM from Neosartorya hiratsukae to control Drechslera oryzae}

Nano-NHM derived from $N$. hiratsukae MST at the concentration of $10 \mathrm{ppm}$ expressed the growth of $D$. oryzae (brown leaf spot of rice) in greenhouse after treated every 7 days for 4 weeks. DI inT1 (inoculated control with D. oryzae) was $4.5,3.5$ and 6.0 at 1,2 and 4 weeks, respectively. T2 (Nano-NHM) showed DI 4.75, 4.5 and 5.0 while T3 (carbendazim) showed DI at 4.5, 4.5 and 4.00 after 1,2 and 4 weeks, respectively (Table 1). The infected rice seedlings var Korkor1 was not significantly decreased in T2 and T3 when comparted with inoculated control with $D$. oryzae (Table4). Many researchers reported that living spores of $N$. fischeri, $N$. glabra, N. hiratsukae, N. takakii and N. tatenoi gave a good control chilli anthracnose caused by Colletotrichum capsici [7]. Results showed that nano-NHM derived from $N$. hiratsukae gave significantly higher number of tillers, plant height and roots, fresh weight of plant and dry weight of plants and roots which were 16, tillers $102 \mathrm{~cm}, 37 \mathrm{~g}, 5 \mathrm{~g}$ and $1.5 \mathrm{~g}$, respectively, than the carbendazim treatment which were 10 tillers, $78 \mathrm{~g}, 22 \mathrm{~g}, 2.8 \mathrm{~g}$ and 0.73 g., respectively (Table \%). Nano-NHM showed a potent to promote plant growth of rice var Korkorl in greenhouse trial which significantly better the carbendazim chemical fungicide. Interestingly, similar research finding found that the tested nano-particles from Chaetomium spp. caused pathogenicity lost of rice blast pathogen. Moreover, nano-CBH from Chaetomium brasiliense treated to rice leaves proved to produce Sakuranertin and Oryzalexin B as phytoalexin against blast disease [17].

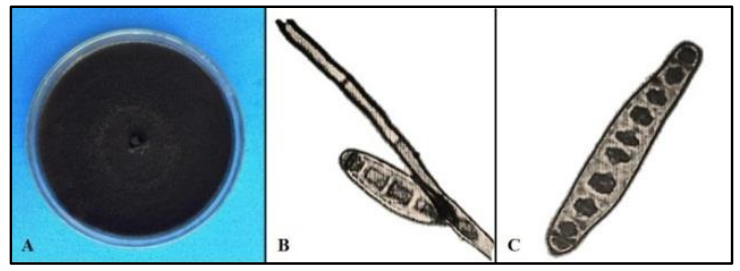

Figure 1. Drechslera oryzae $; \mathrm{A}=$ colony on $\mathrm{PDA}, \mathrm{B}=$ conidium and conidiophre, $\mathrm{C}=$ conidium

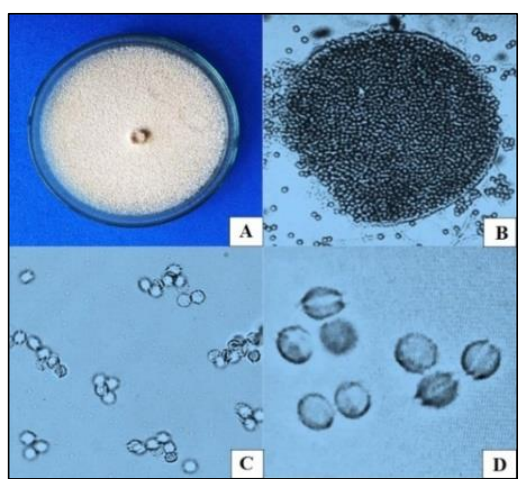

Figure 2. Neosartorya hiratsukae; $\mathrm{A}=$ colony on potato dextrose agar at 30 days, $\mathrm{B}=$ ascocarp and asci, $\mathrm{C}=$ ascospores, $\mathrm{D}=$ ascospores. 


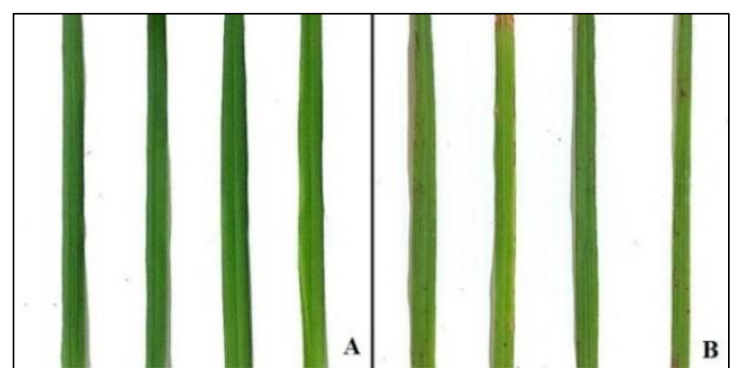

Figure 3. Pathogenicity test $A=$ non-inoculated with Drechslera oryzae, $\mathrm{B}=$ non-inoculated with Drechslera oryzae

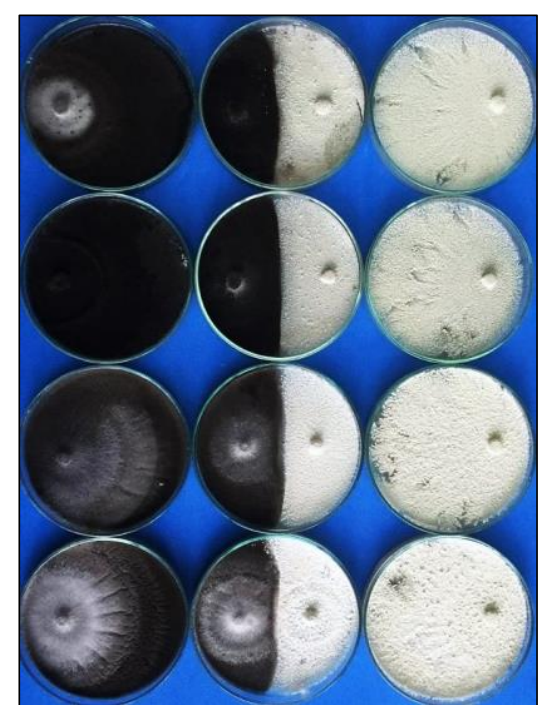

Figure 4. Bi-culture test between Neosartorya hiratsukae and Drechslera oryzae

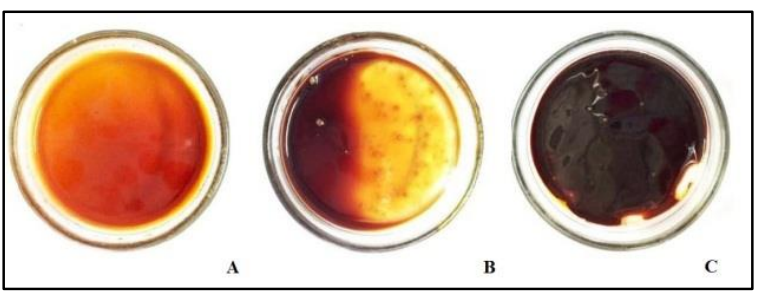

Figure 5. Crude extracts of Neosartorya hiratsukae strain MST, $\mathrm{A}=$ crude hexane, $\mathrm{B}=$ crude, ethyl acetate, $\mathrm{C}=$ crude methanol

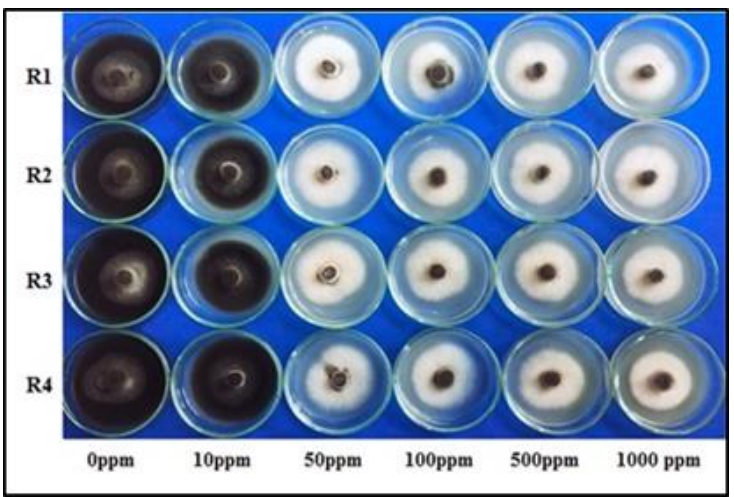

Figure 6. Crude methanol extract of Neosartorya hiratsukae against Drechslera oryzae

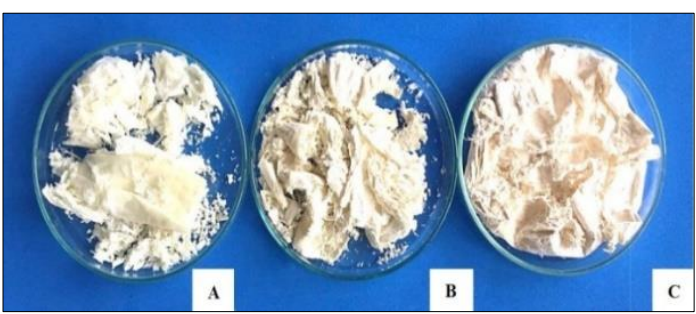

Figure 7. Nanoparticles of Neosartorya hiratsukae; $\mathrm{A}=$ nano-NHH, $\mathrm{B}=$ nano-NHE and $\mathrm{E}=$ nano-NHM 


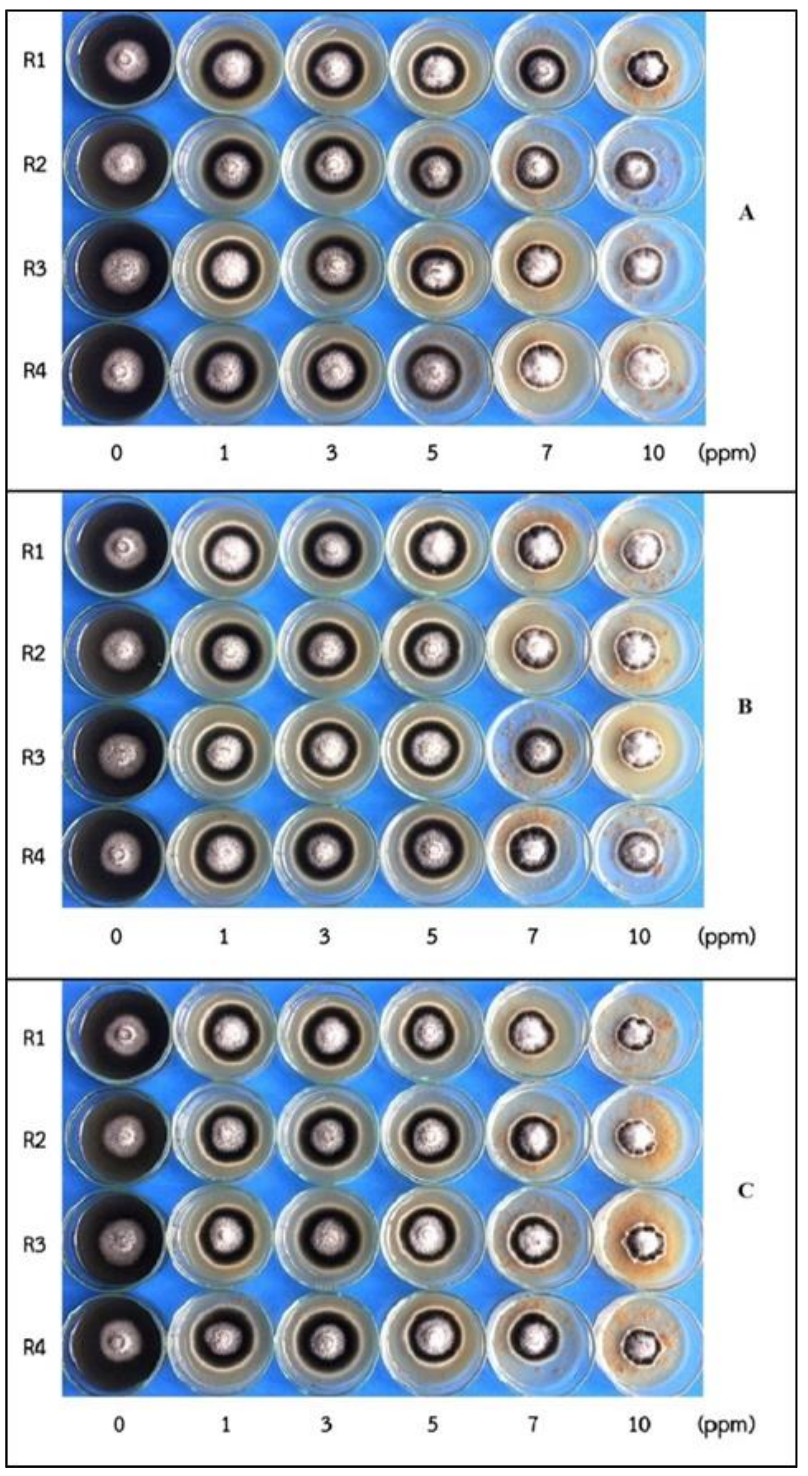

Figure 8. Nanoparticles constructed from Neosartorya hiratsukae strain MST against Drechslera oryzae ; A= nano $-\mathrm{NHH}, \mathrm{B}=$ nano-NHE and $\mathrm{E}=$ nano-NHM
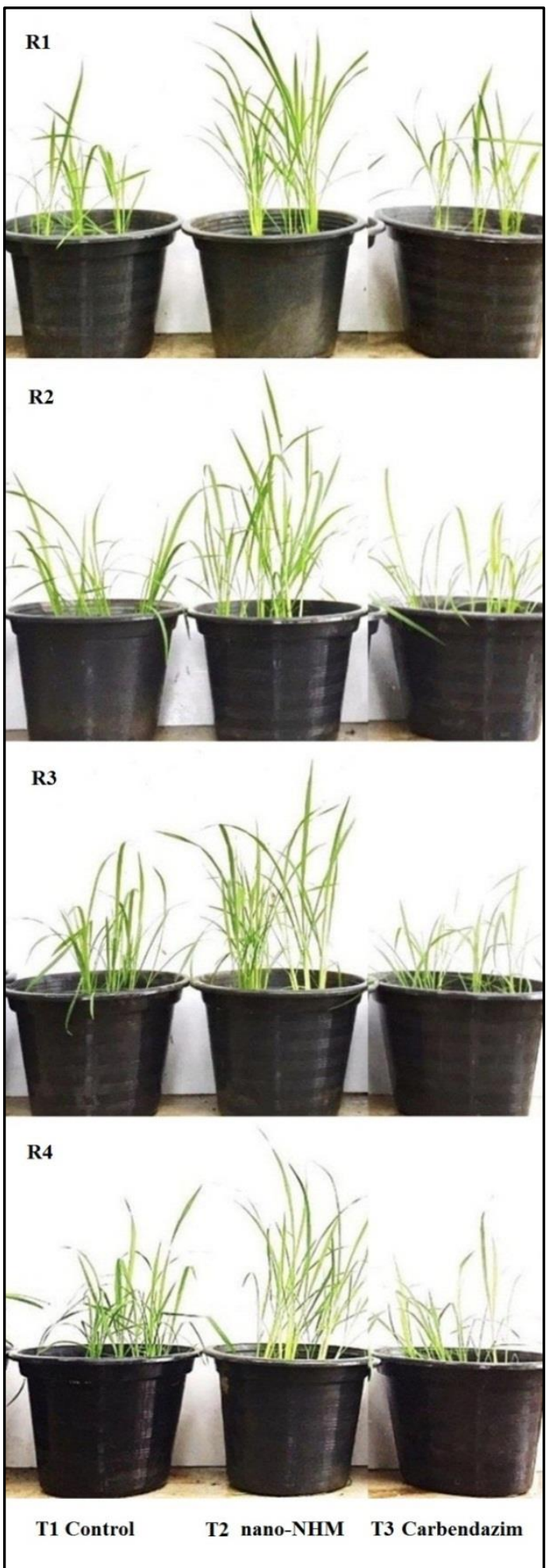

Figure 9. Pot experiment testing for efficacy of nano NHM from Neosartorya hiratsukae to control brown leaf spot of rice 
Table 1. Inhibition of Drechslera oryzae treated with crude extract of Neosartorya hiratsukae strain MST

\begin{tabular}{|c|c|c|c|c|}
\hline $\begin{array}{c}\text { Crude } \\
\text { extracts }\end{array}$ & $\begin{array}{l}\text { Conc. } \\
\text { (ppm) }\end{array}$ & $\begin{array}{c}\text { spore } \\
\text { number } \\
\left(\mathbf{1 0}^{5}\right)\end{array}$ & $\begin{array}{c}\text { inhibition } \\
(\%)\end{array}$ & $\begin{array}{c}\text { ED }_{50} \\
(\mathrm{ppm})\end{array}$ \\
\hline \multirow{6}{*}{ Hexane } & 0 & $3.01^{\mathrm{a}}$ & $0.00^{\mathrm{e}}$ & \multirow{6}{*}{ - } \\
\hline & 10 & $1.68^{\text {cde }}$ & $43.53^{\mathrm{cd}}$ & \\
\hline & 50 & $1.78^{\mathrm{cd}}$ & $38.82^{\text {cd }}$ & \\
\hline & 100 & $1.94^{\mathrm{c}}$ & $34.86^{\mathrm{d}}$ & \\
\hline & 500 & $1.86^{\mathrm{cd}}$ & $36.84^{\mathrm{d}}$ & \\
\hline & 1000 & $1.53^{\text {cde }}$ & $48.76^{\mathrm{cd}}$ & \\
\hline \multirow{6}{*}{$\begin{array}{l}\text { Ethyl } \\
\text { acetate }\end{array}$} & 0 & $3.01^{\mathrm{a}}$ & $0.00^{\mathrm{e}}$ & \multirow{6}{*}{544.44} \\
\hline & 10 & $2.50^{\mathrm{b}}$ & $15.33^{\mathrm{e}}$ & \\
\hline & 50 & $2.66^{\mathrm{ab}}$ & $9.87^{\mathrm{e}}$ & \\
\hline & 100 & $1.78^{\mathrm{cd}}$ & $40.09^{\mathrm{cd}}$ & \\
\hline & 500 & $1.44^{\mathrm{def}}$ & $50.86^{\text {bcd }}$ & \\
\hline & 1000 & $1.28^{\mathrm{ef}}$ & $55.91^{\mathrm{bc}}$ & \\
\hline \multirow{7}{*}{ Methanol } & 0 & $3.01^{\mathrm{a}}$ & $0.00^{\mathrm{e}}$ & \multirow{6}{*}{1.71} \\
\hline & 10 & $0.99^{\mathrm{f}}$ & $66.66^{\mathrm{b}}$ & \\
\hline & 50 & $0.24^{\mathrm{g}}$ & $91.55^{\mathrm{a}}$ & \\
\hline & 100 & $0.14^{\mathrm{g}}$ & $95.12^{\mathrm{a}}$ & \\
\hline & 500 & $0.10^{\mathrm{g}}$ & $96.37^{\mathrm{a}}$ & \\
\hline & 1000 & $0.09^{\mathrm{g}}$ & $96.94^{\mathrm{a}}$ & \\
\hline & $\begin{array}{l}\text { C.V. } \\
(\%)\end{array}$ & 18.82 & 25.37 & \\
\hline
\end{tabular}

"Means of four replications, means followed by the same letters are not significantly differed by DMRT at $P=0.005$
Table 2. Growth inhibition of Drechslera oryzae treated with nanoparticles constructed from Neosartorya hiratsukae strain MST

\begin{tabular}{|c|c|c|c|c|}
\hline $\begin{array}{c}\text { Nano- } \\
\text { particles }\end{array}$ & $\begin{array}{l}\text { Conc. } \\
\text { (ppm) }\end{array}$ & $\begin{array}{l}\text { Colony } \\
\text { dia. } \\
\text { (cm.) }\end{array}$ & $\begin{array}{c}\text { Inhibition } \\
(\%)\end{array}$ & $\begin{array}{c}\text { ED }_{50} \\
(\mathbf{p p m})\end{array}$ \\
\hline \multirow{6}{*}{$\begin{array}{l}\text { Nano- } \\
\mathrm{NHH}\end{array}$} & 0 & $5.00^{\mathrm{al}}$ & $0.00^{\mathrm{i}}$ & \multirow{6}{*}{8.70} \\
\hline & 1 & $3.57^{\mathrm{b}}$ & $28.50^{\mathrm{g}}$ & \\
\hline & 3 & $3.42^{\mathrm{c}}$ & $31.50^{\mathrm{g}}$ & \\
\hline & 5 & $2.97^{\mathrm{d}}$ & $40.50^{f}$ & \\
\hline & 7 & $2.52^{\mathrm{f}}$ & $49.50^{\mathrm{d}}$ & \\
\hline & 10 & $2.27^{\mathrm{g}}$ & $54.50^{c}$ & \\
\hline \multirow{6}{*}{$\begin{array}{l}\text { Nano- } \\
\text { NHE }\end{array}$} & 0 & $5.00^{\mathrm{al}}$ & $0.00^{\mathrm{i}}$ & \multirow{6}{*}{5.28} \\
\hline & 1 & $2.97^{\mathrm{d}}$ & $40.50^{\mathrm{f}}$ & \\
\hline & 3 & $2.92^{\mathrm{de}}$ & $41.50^{\mathrm{ef}}$ & \\
\hline & 5 & $2.92^{\mathrm{de}}$ & $41.50^{\mathrm{ef}}$ & \\
\hline & 7 & $2.22^{\mathrm{g}}$ & $55.50^{c}$ & \\
\hline & 10 & $1.99^{\mathrm{h}}$ & $60.00^{b}$ & \\
\hline \multirow{7}{*}{$\begin{array}{l}\text { Nano- } \\
\text { NHM }\end{array}$} & 0 & $5.00^{\mathrm{a}}$ & $0.00^{\mathrm{i}}$ & \multirow{6}{*}{4.73} \\
\hline & 1 & $3.00^{\mathrm{d}}$ & $40.00^{f}$ & \\
\hline & 3 & $2.97^{\mathrm{d}}$ & $40.50^{\mathrm{f}}$ & \\
\hline & 5 & $2.80^{\mathrm{e}}$ & $44.00^{\mathrm{e}}$ & \\
\hline & 7 & $2.29^{\mathrm{g}}$ & $54.00^{c}$ & \\
\hline & 10 & $1.79^{\mathrm{i}}$ & $64.00^{\mathrm{a}}$ & \\
\hline & $\begin{array}{l}\text { C.V. } \\
(\%)\end{array}$ & 3.09 & 5.02 & \\
\hline
\end{tabular}

"Means of four replications, means followed by the same letters are not significantly differed by DMRT at $P=0.005$ 
Table 3. Spore inhibition of Drechslera oryzae treated with nanoparticles constructed from Neosartorya hiratsukae strain MS

\begin{tabular}{|c|c|c|c|c|}
\hline Nano-particles & Conc. (ppm) & Spore number $\left(10^{5}\right)$ & Inhibition (\%) & ED50 (ppm) \\
\hline \multirow{6}{*}{ Nano-NHH } & 0 & $4.23^{\mathrm{al}}$ & $0.00^{\mathrm{h}}$ & \multirow{6}{*}{4.60} \\
\hline & 1 & $3.56^{\mathrm{b}}$ & $15.71^{\mathrm{g}}$ & \\
\hline & 3 & $3.06^{\mathrm{cd}}$ & $27.26^{\mathrm{ef}}$ & \\
\hline & 5 & $2.80^{\mathrm{de}}$ & $33.79^{\mathrm{de}}$ & \\
\hline & 7 & $1.31^{\mathrm{g}}$ & $68.89^{\mathrm{b}}$ & \\
\hline & 10 & $0.47^{\mathrm{h}}$ & $88.74^{\mathrm{a}}$ & \\
\hline \multirow{6}{*}{ Nano-NHE } & 0 & $4.23^{\mathrm{a}}$ & $0.00^{\mathrm{h}}$ & \multirow{6}{*}{4.11} \\
\hline & 1 & $3.34^{\mathrm{bc}}$ & $20.75^{\mathrm{fg}}$ & \\
\hline & 3 & $3.35^{\mathrm{bc}}$ & $20.27^{\mathrm{fg}}$ & \\
\hline & 5 & $2.32^{\mathrm{f}}$ & $44.84^{\mathrm{c}}$ & \\
\hline & 7 & $1.24^{\mathrm{g}}$ & $70.66^{b}$ & \\
\hline & 10 & $0.28^{\mathrm{h}}$ & $93.32^{\mathrm{a}}$ & \\
\hline \multirow{6}{*}{ Nano-NHM } & 0 & $4.23^{\mathrm{a}}$ & $0.00^{\mathrm{h}}$ & \multirow{6}{*}{4.63} \\
\hline & 1 & $3.53^{\mathrm{b}}$ & $15.94^{\mathrm{g}}$ & \\
\hline & 3 & $3.52^{\mathrm{b}}$ & $16.51^{\mathrm{g}}$ & \\
\hline & 5 & $2.56^{\mathrm{ef}}$ & $39.53^{\text {cd }}$ & \\
\hline & 7 & $1.44^{\mathrm{g}}$ & $65.69^{\mathrm{b}}$ & \\
\hline & 10 & $0.22^{\mathrm{h}}$ & $94.87^{\mathrm{a}}$ & \\
\hline & C.V. (\%) & 9.06 & 14.63 & \\
\hline
\end{tabular}

Table 4. The efficacy of nano-NHM from Neosartorya hiratsukae to control brown leaf spot of rice in 28 days

\begin{tabular}{|l|c|c|c|c|}
\hline \multicolumn{5}{|c|}{ Disease index } \\
\hline Treatments & days 7 & days 14 & days 28 & $(\%)$ Disease reduction \\
\hline T1) Inoculate control) & $4.50^{\mathrm{a}}$ & $3.50^{\mathrm{a}}$ & $6.00^{\mathrm{a}}$ & 33.3 \\
\hline T2 (nano-NHM) & $4.75^{\mathrm{a}}$ & $4.50^{\mathrm{a}}$ & $4.00^{\mathrm{b}}$ & 33.3 \\
\hline T3 (Carbendazim) & $4.50^{\mathrm{a}}$ & $4.50^{\mathrm{a}}$ & $4.00^{\mathrm{b}}$ & - \\
\hline \multicolumn{1}{|c|}{ CV\% } & 12.06 & 39.19 & 11.17 & \\
\hline${ }^{\prime \prime}$ Means of four replications, means followed by the same letters are not significantly differed by DMRT at P $=0.005$
\end{tabular}


Table 5. The effect of nano-NHM from Neosartorya hiratsukae for plant growth of rice var Korkor1 at 28 days

\begin{tabular}{|l|c|c|c|c|c|}
\hline \multicolumn{1}{|c|}{ Treatments } & tillers & $\begin{array}{c}\text { plant } \\
\text { height } \\
\text { and roots }\end{array}$ & $\begin{array}{c}\text { fresh weight of } \\
\text { plant height and } \\
\text { roots }\end{array}$ & $\begin{array}{c}\text { dried weifght } \\
\text { of plant }\end{array}$ & $\begin{array}{c}\text { dried weight } \\
\text { bof rots }\end{array}$ \\
\hline T1) Inoculate control) & $11.75^{\text {ab }}$ & $87.25^{\mathrm{b}}$ & $27.07^{\mathrm{b}}$ & $4.05^{\mathrm{b}}$ & $0.86^{\mathrm{ab}}$ \\
\hline T2 (Nano-NHM) & $16.50^{\mathrm{a}}$ & $102.00^{\mathrm{a}}$ & $37.15^{\mathrm{a}}$ & $5.39^{\mathrm{a}}$ & $1.53^{\mathrm{a}}$ \\
\hline T3 (Carbendazim) & $10.50^{\mathrm{b}}$ & $78.25^{\mathrm{b}}$ & $22.48^{\mathrm{c}}$ & $2.85^{\mathrm{c}}$ & $0.73^{\mathrm{b}}$ \\
\hline \multicolumn{1}{c}{ CV\% } & 22.01 & 6.96 & 7.67 & 13.16 & 37.76 \\
\hline
\end{tabular}

${ }^{1 /}$ Means of four replications, means followed by the same letters are not significantly differed by DMRT at P =0.005

\section{CONCLUSION}

Neosartorya hiratsukae proved to be suppressed Drechslera oryzae (brown spot of rice). It is effectively inhibited the inocula of $D$. oryzae. The crude metabolite of $N$. hiratsukae is extracted by methanol showed highly antifungal activity to control inhibit the growth and sporulation of $D$. oryzae which the $\mathrm{ED}_{50}$ were 1.7 and 92 ppm., respectively. The biodegradable natural product of nanoparticles, SH-M expressed the highest inhibition of pathogen's sporulation at the $\mathrm{ED}_{50}$ of $4 \mathrm{ppm}$. The nanoparticles constructed from $N$. hiratsukae proved to be effective controlled rice brown spot in pot trials and gave a better plant stands than the control. It has further investigated to develop as a new biological product for plant disease control.

\section{ACKNOWLEDGMENT}

The research project was supported by Association of Agricultural Technology in Southeast Asia (AATSEA).

\section{REFERENCES}

[1] FAO ; Food and Agriculture Organization of the United Nations, Edible insects Future prospects for food and feed security, FAO FORESTRY PAPER, 2013, EISBN 978-92-5-107596-8.

[2] Rice Department, Thailand, Retrieved 2020, from http://www.ricethailand.go.th/web/index.php.

[3] J. P. Gustafson (ed.), IRRI Breeding Program and Its Worldwide Impact on Increasing Rice Production, Gene Manipulation in Plant Improvement (C) Plenum Press, 1984, New York.
[4] J.L. Alcorn, The taxonomy of Helminthosporium species, Annual of phytopathology, 1988, 26: 37-56.

[5] S. Tathan, P. Sibounnavong, P.S. Sibounnavong, K. Soytong, C. To-anun, Biological metabolites from Chaetomium spp to inhibit Drechslera oryzae causing leaf spot of rice, Journal of Agricultural Technology, 2012, Vol. 8(5): 1691-170.

[6] J. Paluka, J. K. Kanokmedhakul, M. Soytong, K. Soytong, Meroterpenoid pyrones, alkaloid and bicyclic brasiliamide from the fungus Neosartorya hiratsukae. Fitoterapia, 2020, 142 (104485): 1-6.

[7] A. Eamvijarn, L. Manoch, N. Visarathanonth, C. Chamsawarng, Diversity of Neosartorya species from soil and In vitro antagonistic test against plant pathogenic fungi. $11^{\text {th }}$ International Marine and Freshwater Mycology Symposium. National, 2009.

[8] A. Punyanobpharat, K. Soytong, S. Poeaim, Effective of Neosartorya and Talaromyces to control Alternaria brassicicola causing leaf spot of kale, International Journal of Agricultural Technology, 2018, Vol. 14(7): 1709-1718.

[9] T. Mangkalad, K. Soytong, N. Tangthirasunun, S. Poeaim, Effective of Neosartorya to control Phomopsis asparagi causing stem blight of asparagus, International Journal of Agricultural Technology, 2018, Vol. 14(7): 1423-1432.

[10] IRRI ; International Rice Research Institute, IRRI Annual Report, 2009.

[11] K. Soytong, Testing bioformulation of Chaetomium elatum ChE01to control Fusarium wilt of tomato, 
Journal of Agricultural Technology, 2015, 11(4):975996.

[12] W. Pattarasaikul, K. Soytong, S. Poeiam, Biological control of anthracnose disease on banana var 'Namwa Mali-Ong' by Neosartorya species, International Journal of Agricultural Technology, 2018,Vol. 14(7): 1589-1598.

[13] R. Vareeket, K. Soytong, S. Kanokmedhakul, K. Kanokmedhakul, Nano-particles from Cheatomium brasiliense against brown spot of rice, International Journal of Agricultural Technology, 2018, Vol. 14(7): 2207-2214.

[14] J. Dar, K. Soytong, Construction and characterization of copolymer nanomaterials loaded with bioactive compounds from Chaetomium species, International Journal of Agricultural Technology, 2014, 10:823-831.
[15] K. Soytong, Bio-formulation of Chaetomium cochliodes for controlling brown leaf spot of rice, International Journal of Agricultural Technology, 2014, Vol. 10(2): 321-337.

[16] J.J. Song, K. Soytong, S. Kanokmedhakul, K. Kanokmedhakul, S. Poeaim, Antifungal activity of microbial nanoparticles derived from Chaetomium spp. against Magnaporthe oryzae causing rice blast, Plant Protect. Sci., 2020a, 56: 180-190.

[17] J.J. Song, K. Soytong, S. Kanokmedhakul, K. Kanokmedhakul, S. Poeaim, Natural product of nanoparticles constructed from Chaetomium spp. to control rice blast disease caused by Magnaporthe oryzae, 2020b, Intl J Agric Biol 23:1013-1020. 